\title{
A TRADIÇÃO DA MÚSICA ERUDITA PORTUGUESA: A SUA CONTEMPORANEIDADE
}

\author{
THE TRADITION OF PORTUGUESE CLASSICAL MUSIC: ITS CONTEMPORANEITY
}

\author{
José Augusto Neves de Moura ${ }^{1}$ \\ António José Pacheco Ribeiro ${ }^{2}$
}

RESUMO: O presente artigo expõe uma reflexão sobre a vida e obra de cinco compositores portugueses relevantes da atualidade: Cândido Lima, João Pedro Oliveira, Sérgio Azevedo, Sara Carvalho e Fernando Lapa, que se movimentam no âmbito da chamada música erudita. Neste sentido, apresenta uma breve biografia dos compositores envolvidos e define o seu percurso como compositores. Por outro lado, faz uma breve análise de uma das suas obras, considerando as suas principais características, assim como as influências possíveis de outros compositores e escolas de composição que determinam aspetos estilísticos predominantes. Em jeito de conclusão, sublinhamse, comummente, traços e princípios identitários composicionais do passado e do presente alicerçados na perspetiva da tradição e inovação.

Palavras-chave: Compositores Portugueses. Música Erudita. Traços Estilísticos. Tradição e Inovação.

ABSTRACT: This paper presents a reflection on the life and work of five relevant current Portuguese composers: Cândido Lima, João Pedro Oliveira, Sérgio Azevedo, Sara Carvalho and Fernando Lapa, who move within the so-called classical music. In this sense, it presents a brief biography of the composers involved and determines their path as composers. On the other hand, it makes a brief analysis of one of their works, considering its main characteristics, as well as the possible influences of other composers and schools of composition that determine predominant stylistic traits. As a conclusion, the compositional identity traits and principles of the past and the present based on the perspective of tradition and innovation are commonly underlined.

Keywords: Portuguese Composers. Classical Music. Stylistic Traits. Tradition and Innovation.

\footnotetext{
${ }^{1}$ Doutorando em Estudos da Criança - Educação Artística (Educação Musical), na Universidade do Minho, sob a orientação do Professor António Pacheco e coorientação da Professora Maria Helena Vieira. O seu interesse de pesquisa centra-se no ensino artístico especializado da música em Portugal, mais concretamente na área da composição musical, área na qual tem desenvolvido diversos projetos, quer nas escolas de ensino artístico, quer em instituições de cariz social. Leciona no Conservatório de Música de Felgueiras, Fórum Cultural de Gulpilhares, e no Instituto Superior de Ciências Educativas-Douro. Mestre em Ensino de Música-Composição, pela mesma Universidade Licenciado em Música pela Universidade de Aveiro. Membro colaborador do Centro de Investigação em Estudos da Criança (CIEC).Email: josemoura69@gmail.com. ORCID: oooo-oooz-6170-8737

${ }^{2}$ Doutor na Especialidade de Educação Musical, em Estudos da Criança, na Universidade do Minho. Mestre em Estudos da Criança - Especialização em Educação Musical pela Universidade do Minho. Realizou a parte letiva do Curso de Mestrado em Etnomusicologia na Universidade de Aveiro. Licenciado em Ensino de Música pela Universidade de Évora. O seu interesse de pesquisa centra-se no ensino artístico especializado da música em Portugal, e na etnomusicologia e música tradicional, áreas em que tem desenvolvido diversos projetos de interação com a sociedade. Leciona no Conservatório do Vale do Sousa, Lousada, e no Instituto de Educação da Universidade do Minho. É membro integrado do Centro de Investigação em Estudos da Criança (CIEC). E-mail: antoniopacheco@ie.uminho.pt. ORCID: oooo-ooo3-34138473
} 


\title{
I INTRODUÇÃO
}

Ao fazer uma abordagem sobre os principais nomes dos compositores de música portuguesa da atualidade (independentemente da opção para este artigo), leva-nos a colocar a seguinte questão: que tipo de música portuguesa e o que se entende por música portuguesa? Neste contexto, esclarece-se que este trabalho se desenvolve no âmbito da chamada música erudita e que o conceito de música portuguesa se aplica a compositores portugueses que determinam, nas suas composições, influências da cultura portuguesa. A escolha destes cinco compositores, para este artigo, obedeceu, assim, a estes princípios e a uma preferência pessoal, estando certo que outros compositores se inseririam nesta perspetiva e, que, por questão de opção, foram excluídos. A escolha das obras para análise foi determinada pelas considerações estilísticas acima mencionadas.

\section{Estado da arte}

Não querendo entrar por uma divagação excessivamente detalhada em formato de catálogo sobre a música erudita portuguesa no século XX e XXI, apresento uma visão concreta, considerando os compositores selecionados, sobre a música portuguesa destes dois séculos, referenciando padrões, qualidades, características estilísticas e influências que decorrem em parte de um paradigma ideológico em Portugal.

\begin{abstract}
$\mathrm{Na}$ sua expressão mais estereotipada (e por isso mesmo, mais reveladora), esse paradigma poderia resumir-se à dicotomia entre os termos modernidade $\mathrm{e}$ antimodernidade - à qual, nas últimas décadas, se viria acrescentar uma pósmodernidade de incerta definição (CASTRO, 2015, p. 216).
\end{abstract}

Durante o século XX assistimos em Portugal a um conjunto de transformações políticas, económicas, sociais e culturais. A nível político, a queda da monarquia, a nível económico o fim de um sistema ditador e a ascensão de um sistema político republicano e democrático e após a revolução democrática de 25 de abril de 1974 vamos assistir ao crescimento da atividade cultural de algumas cidades como Coimbra, Aveiro e Faro. A nível social vamos encontrar em Portugal uma sociedade rural, religiosa e alicerçada por uma economia familiar. Em relação à cultura, vamos assistir a uma mudança de paradigma; no que diz respeito à música, as velhas estruturas do passado são colocadas em causa dando lugar a um novo conceito de música (CASTRO, 2015).

$\mathrm{Na}$ primeira metade do século $\mathrm{XX}$ vamos assistir a um desfasamento relativamente aos grandes centros da Europa por força de um Portugal fechado em si próprio, estagnado, por oposição a um tempo evolutivo, tempo de modernidade. Este problema dos diferentes tempos, pode ser encontrado nos padrões estruturais de um determinado compositor ou por um estilo de composição, que nos pode fornecer um interessante fio condutor para a melhor compreensão sobre o modo como uma época ou uma sociedade se pode pensar a si próprios (CASTRO, 2015).

O etnólogo e antropólogo Jorge Dias em 1950 baseando-se nas observações do musicólogo Santiago Kastner referiu o seguinte:

Mas na música repete-se exatamente o mesmo fenómeno. Em quase todos os compositores se verifica a imobilidade, o apego a meia dúzia de desenhos musicais fixos, às sequências obstinadas $[\ldots]$. O «ostinatismo» que se verifica na música 
erudita portuguesa [...], é um dos aspetos do temperamento português, que se pode notar em outras manifestações artísticas (DIAS, 1985, p. 45-46 apud CASTRO, 2015, p. 217).

Podemos deduzir pelas palavras de Dias que, de uma forma geral, o pensamento regressivo do povo português, em meados do século $X X$, foi um entrave para um pensamento dinâmico e moderno que já se vinha manifestando um pouco por toda a Europa.

À imagem de outros compositores portugueses que se debateram com problemas semelhantes no passado, tais como: João Domingos Bomtempo (1775-1842: o reformista); José Viana da Mota (I868-1948), com a sua sinfonia A Pátria em Lá Maior, composta em 1894-5, que tinha como objetivo implantar o culto pela sinfonia, vamos encontrar um conjunto de personalidades que com a ajuda dos meios de comunicação vão permitir uma mudança de paradigma no meio musical português, decadente e estagnado (CASTRO, 2015).

Luís de Freitas Branco (1890-1955), no início do século XX, foi considerado o introdutor do modernismo musical em Portugal. As suas viagens pela Europa fizeram dele um cosmopolita, nomeadamente em Berlim (onde estudou com Humperdinck) e Paris (onde contatou com Grovlez, discípulo de Fauré) mantendo sempre uma ligação como o mundo rural alentejano, mas ao mesmo tempo evidenciava um certo ceticismo no que diz respeito ao aproveitamento erudito da música popular. Freitas Branco hesitou sempre entre o simbolismo de Strauss, Debussy e Ravel, e os rigores da escrita severa descendência franckista e scholista, sem esquecer a influência do seu mestre Désiré Pâque, organista e compositor belga residente em Lisboa a partir de 1904, que terá influenciado Freitas Branco a uma abordagem pioneira pela linguagem atonal. Freitas Branco era um jovem audaz e criativo e muito empenhado na exploração de uma poética de suspensão temporal e irresolução das funções harmónicas, bastante evidente no seu poema sinfónico Vathek, inspirado no famoso conto oriental de William Beckford (CASTRO, 2015).

Fernando Lopes-Graça (1906-1994), a partir de 1920, é incontornavelmente, a principal figura do panorama musical português, apresentando-se como um opositor ao regime político da época, facto que o levou a ter uma carreira como compositor à margem dos circuitos institucionais. A sua obra pode-se caracterizar como um modernismo moderado. A linguagem musical das obras de Fernando Lopes-Graça, tem uma forte influência de Tomás Borba, Viana da Mota e Luís de Freitas Branco, que foram seus professores. Mais tarde, aquando da sua permanência em Paris entre 1937 e 1939, onde contactou com Charles Koechlin, alterou um pouco a sua forma de compor, fazendo adaptações de canções populares portuguesas. Neste sentido João José Cochofel diz o seguinte:

[U]ma linguagem harmónica livre, mas de base funcional, um dissonantismo diatónico, uma rítmica percutiva alternando com uma polirritmia linear (o que leva a uma grande variedade de metros e ao frequente abandono do compasso), enfim, e do ponto de vista da expressão, um lirismo claro e terso, de raiz popular e mais propriamente peninsular (COCHOFEL, 1958, p. 138-139 apud CASTRO, 2015, p. 236).

Ao longo dos anos 40 e 60 do século passado, Lopes-Graça envidou uma extensa recolha do material folclórico português, no sentido de encontrar na música popular tradicional portuguesa uma fonte para a construção de uma linguagem musical própria. De facto, a linguagem musical de Fernando Lopes-Graça é inevitavelmente marcada pelo seu carácter nacionalista e o seu interesse pelas canções populares surgiu como resultado da sua 
procura em criar uma linguagem musical própria e identitária (MOREIRA, 2014). É de realçar ainda as influências no seu estilo de compor de compositores como: Debussy, Stravinsky, Falla e Bartók. Fernando Lopes-Graça compôs em quase todos os géneros e formações musicais exceto a ópera.

Jorge Peixinho (1940-1995), é outro compositor importante que merece ser referenciado no panorama musical português. Perante um contexto político ditatorial, de portas fechadas ao exterior e ao modernismo, Jorge Peixinho faz as primeiras incursões nas décadas de 6o e 70 na música de vanguarda. Frequentou os Cursos de Darmstadt na década de 6o, teve como referência compositores como, Karlheinz Stockhausen, Pierre Boulez e, principalmente, Luigi Nono, devido à sua obra muito associada a questões políticas. Estas referências levam Jorge Peixinho a enveredar por um estilo de composição mais direcionado à experimentação tímbrica, com recurso aos meios e técnicas eletroacústicas. Numa entrevista ao Diário de Lisboa é referido o seguinte a seu propósito:

[...] a vanguarda é essencialmente revolucionária, em relação a todos os valores ideológicos, estéticos e morais. Tende para a subversão dos pseudovalores herdados de uma sociedade ultrapassada e cristalizada, de uma sociedade vegetativa e em decomposição (CASTRO, 2015, p. 239).

Perante esta rutura com o passado, com as tradições, com as estruturas seculares, caminhamos agora para uma revolução/renovação no panorama musical português, com as portas abertas para o exterior, abrindo caminho para um novo paradigma da música portuguesa. É desta forma que vamos ter um novo ciclo na vida musical portuguesa que se vai prolongar até aos dias de hoje: Clotilde Rosa (1930); Filipe Pires (1934); Constança Capdeville (1937-1992); Álvaro Salazar (1938); Cândido Lima (1939); Emmanuel Nunes (19412012), este de um pensamento musical de grande rigor e complexidade. Mais recentemente, António Pinho Vargas; João Pedro Oliveira; António Chagas Rosa; Miguel Azguime; Isabel Soveral; Eurico Carrapatoso; Alexandre Delgado; Sérgio Azevedo; Fernando Lapa; Sara Carvalho, entre outros.

\section{Breve biografia de Cândido Oliveira Lima}

Cândido Oliveira Lima (1939), pianista e compositor, diplomado nos Conservatórios de Música de Lisboa e Porto, onde viria a lecionar mais tarde, assim como na Escola Superior de Música do Porto, residiu à Juventude Musical de Braga e administrou o Conservatório de Música do Porto e o Conservatório Fundação Calouste Gulbenkian de Braga. Foi bolseiro da Fundação Calouste Gulbenkian e da Secretaria de Estado da Cultura. Diplomado em Filosofia e Humanidades na Faculdade de Filosofia da Universidade do Minho e Doutorado pela Universidade de Paris I - Sorbonne. Estudou composição com Iánnis Xenakis e Direção de Orquestra com Gilbert Amy e Michel Tabachinik. Foi pioneiro em Portugal na utilização das novas ferramentas para a criação musical, nomeadamente na utilização do computador, eletroacústica e orquestra, tendo estudado eletroacústica e informática musical nas Universidades de Vincennes e Panthéon-Sobornne onde estagiou no Institut for Research and Coordination in Acoustics/Music (IRCAM) e no Centre d'Études de Mathématique et Automatique Musicales (CEMAMu). Foi responsável pela vinda de alguns dos grandes nomes do panorama musical mundial a Portugal: Iánnis Xenakis; Gyorgy Ligeti e Pierre Boulez. Em 1973, com o intuito de promover a música e os compositores portugueses, funda 
o Grupo Música Nova. Autor de várias séries de televisão, tais como: Sons e mitos; Fronteiras da música; No Ventre da Música; Evocações; para a rádio foi responsável pelo programa De toda a música. Autor de vários livros, nomeadamente: A música e o homem na reforma do ensino: da antiguidade à vanguarda (1974); Xenakis et la Pédagogie, ou les Mythes (198I); Perspectivas do Ensino da Composição em Portugal (198I); Os arquétipos na Composição Musical (com conceitos da filosofia e ciências) (1983); Canções para a juventude: Canto e piano (2000); Segredos e origens da Música Portuguesa Contemporânea - Música em som e imagem (2003). É colaborador da Enciclopédia Verbo desde 1972. Foi convidado por Pascal Dusapin, que lhe dedicou a obra Canto, a integrar o júri de seleção da Académie Européènne de Composition, com W. Rhim, M. Lindberg, K. Huber, G. Benjamin e J. Dillon.

\title{
3.I Características e influências na obra de Cândido Oliveira Lima
}

A necessidade do compositor em exteriorizar e partilhar as suas experiências, no que diz respeito à manipulação dos sons, assim como a partilha do seu conhecimento, faz com que seja um compositor de referência no panorama musical português na atualidade. A sua obra, apesar de algumas contradições, concilia aquilo a que podemos apelidar como, a linguagem do passado com a nova linguagem.

\begin{abstract}
A combinatória no sentido lato e estrito, o indeterminismo e o controlo na sua ampla acepção convivem com estruturas livremente tratadas ao longo do devir musical. A fenomenologia do som, a monadologia como filosofia do intervalo, do som-timbre e da cor, da espacialização e do tempo teatral e cinematográfico, tudo coexiste com técnicas diversas oriundas da prática musical específica e de outros domínios (LIMA, 2002, p. 79).
\end{abstract}

\section{Obra: Toiles}

O compositor demostra o seu profundo conhecimento e domínio quanto às técnicas de compor do passado, tais como: a repetição, a variação, a transposição, a derivação, assim como a reutilização sistemática do material temático, como por exemplo, estruturas musicais baseadas num intervalo musical, conjugando com outras áreas do conhecimento como a matemática, a física, muito presente na maioria das suas composições, bem como os novos meios de produção musical, mais concretamente as tecnologias, as novas ferramentas agora ao dispor dos compositores. A procura de novas sonoridades proporcionadas pelas novas ferramentas ao seu dispor estão bastante presentes na sua obra Toiles, onde Cândido Lima refere o seguinte numa entrevista a Azguime:

Foi pensada enquanto obra sonora, enquanto espaço sonoro e espaço plástico. Tem uma série de rolos em forma de pergaminhos com várias partituras, com a linear, a 3 dimensões, com 5 cores para destrinçar as 5 famílias das suas cordas...mas foi pensado, de facto, como se eu pudesse estar ao mesmo tempo a escrever em pauta e em clave e ao mesmo tempo a desenhar aquilo e a fazer uma espécie de Kandinskiana ou talvez Mondriana ou aquele outro... [pensamos nós que se refere a Malevitch] que é uma espécie de quadro branco a partir do qual se iriam fazendo iluminações na partitura (AZGUIME, 2004, s. p. apud SANTANA, H.; SANTANA, R., 2015, p. 90). 
O interesse pelos meios audiovisuais e pela música eletroacústica, são aspetos que estão presentes na maioria das suas obras. Ainda a este propósito, as suas obras, Autómatos da Areia (1978/84), Lendas de Neptuno (1987), e Oceanos (1978/99) a que o compositor denominou de Toiles, foram inspiradas aquando da sua permanência na Guerra de Ultramar (Guiné-Bissau) e que na opinião do compositor são "[...] painéis que se cruzam, como os tranquilos tapetes aquáticos dos mares de Bissau, memórias de I966 a 1968” (LIMA, 2002, p. 88 apud SANTANA, H; SANTANA, R., 2015, p. 89).

É de referir que o compositor, posteriormente, vai reutilizar algumas destas obras, reescrevê-las e até mesmo manipulá-las em outras das suas obras, tais como: Toiles II (19781980; música por computador (UPIC-I, fita magnética) em Oceanos e Toiles IV (1978-198o; música por computador UPIC - I e II, síntese analógica) em Lendas de Nepturno; Toiles III (1978-I98I; música por computador UPIC-II, fita magnética) permanecerá, originalmente, como peça autónoma.

$\mathrm{Na}$ sua obra podemos encontrar uma combinação entre elementos da cultura portuguesa e a cultura africana, nomeadamente da Guiné-Bissau, o que incute à obra de Cândido Lima uma sonoridade muito pessoal e única. Essa combinação entre as duas culturas está presente em várias obras do compositor, tais como: Nô, African Ryt(hm)os, Ritos de África, Missa Mandinga, Canções de Ur, Ncàãncôa, Nanghê.

\begin{abstract}
As minhas fontes em composição confundem-se no contacto da infância, na aldeia, com músicas populares, de romaria, religiosas e com sons da natureza: do silencio, do mar, do campo e da montanha. A aprendizagem de adolescência no contacto vivo com prática religiosa de cunho afro-asiático (o tempo e o espírito) ou de cunho estóico (filosofia cristã e pré-cristã), com a cultura clássica greco-latina (ritmo e verbo), com o canto gregoriano (o modalismo e o contínuo), com a polifonia (contraponto), com a prática coral e organística (do Barroco ao séc. XX) e a absorção natural e inconsciente destas vivências com épocas e práticas musicais diversas, na convivência juvenil tardia com os meios académicos dos Conservatórios e seus programas românticos, tudo informou a minha música (se é minha...) desde a idade de is anos até hoje (LIMA, 2002, p. 79).
\end{abstract}

As suas vivências associadas às estruturas rítmicas e temporais, assim como a forma como desenvolve estes elementos, estão presentes em alguns gestos e na forma como manipula os sons. A nível orquestral e vocal também é possível encontrar na obra de Cândido Lima algumas dessas influências africanas. Neste sentido, Azevedo refere o seguinte:

[...] o Outro e a ideia de música na forma das exóticas, primordiais culturas extraeuropeias... [se expressa em obras como] Nô, Ritmos de África, Missa Mandinga, 4 canções de Timor, Canções de Ur, Ncàãncôa, Nanghê... ${ }^{3}$ essa máscara que esconde o verdadeiro [artista. Será então que a obra serve para afrontar as forças criativas e impositivas de uma katharsis criativa mais ou menos velada $e$ manifesta, ou será que serve para o compositor se esconder do outro, da vida e do existir que o imerge e transmuda de forma violenta e gutural? E Cândido Lima será, então, real?] Não será antes o homem vários homens, heteronomicamente, pessoanamente divididos entre a tentativa de exprimir o todo e o saber de antemão que esse Todo não o poderemos nunca abarcar? (AZEVEDO, 2002, p. 14).

${ }^{3}$ Nô (1986-88), Ritmos de África (1967), Ritos de África (1966), Missa Mandinga (1966), 4 Canções de Timor (1995), Canções de Ur (1987), Ncàãncôa (I ${ }^{\mathrm{a}}$ versão 1995; $2^{\underline{a}}$ versão 2002), Nanghê (1990). 

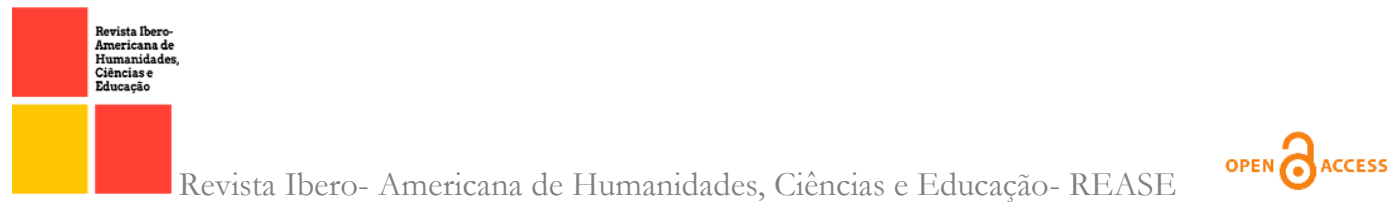

Nas obras Ncàãncôa e Sang-ge-Sang podemos encontrar um tempo e um espaço que denotam um novo olhar sobre si e a realidade ${ }^{4}$.

\section{Breve biografia de João Pedro Oliveira}

João Pedro Oliveira (1959), compositor e organista, fez a sua formação em Órgão no Instituto Gregoriano de Lisboa. Mais tarde, como Bolseiro da Fundação Calouste Gulbenkian e da Comissão Cultural Luso-Americana, estudou Composição em Nova Iorque, onde concluiu os Mestrados em Composição e Teoria da Música e, posteriormente, Doutoramento em Composição. Além da sua atividade profissional como compositor, é professor associado na Universidade de Aveiro, Diretor do Centro de Investigação em Música Eletroacústica do Departamento de Comunicação e Arte da mesma Universidade, conferencista e autor de diversos escritos e tem tido um papel preponderante no estudo da análise musical, para o qual muito contribuiu com o seu livro Teoria Analítica da Música do Século XX (TELLES, 2019).

No ano de 1978, as várias digressões que fez como organista pela Europa, Estados Unidos da América, China e Japão até ao ano 200o, coincidiram com os seus primeiros passos na Composição. Segundo o João Pedro Oliveira: "O órgão teve um papel importante na minha actividade durante vários anos" (SALAZAR, 2003, p. 9I).

O contacto com a música contemporânea foi através da obra Dieu parmi nous, de Olivier Messiaen, o fascínio pelas técnicas e tendências recentes no seu tempo de estudante. Segundo o compositor “[...] esse contacto só foi possível graças à abertura do seu professor, Antoine Sibertin-Blanc, a tendências estéticas recentes, relativamente às quais as classes de piano, por exemplo, eram, à época, muito mais reservadas" (SALAZAR, 2003, p. 9I). Este contacto com a música contemporânea para órgão influenciou muito o compositor na sua prática composicional, como se pode verificar pelas seguintes palavras:

[...] quando exercia a atividade de organista e realizava concertos, a alternância entre as duas atividades era muito estimulante para a criatividade. Certos problemas e soluções relacionados com a composição tornaram-se mais claros ao estar em contacto direto com a música, através do ato de tocar. E muitas vezes, soluções propostas pelos compositores que eu tocava (clássicos e contemporâneos), serviam de modelo ou estímulo para as minhas próprias obras (OLIVEIRA, 2017, p. Io).

O facto de um músico instrumentista tocar obras de outros compositores não impede que possamos ser criativos na execução das obras, e os conhecimentos na área da composição podem ser um estímulo para essa criatividade.

$\mathrm{Na}$ sua vasta obra temos mais de Ioo composições: uma ópera, música orquestral e coral, música de câmara, obras para instrumento solo, obras de fita/eletroacústica, vídeo, música para espaços públicos, orquestrações e diversos arranjos. Em relação à discografia, II

\footnotetext{
${ }_{4} \mathrm{Na}$ sua obra Ncàãncôa podemos verificar uma primeira versão de 1995 para clarinete e espacialização eletroacústica, cuja primeira audição teve lugar em Lisboa no ano seguinte, e uma segunda versão de 2002 para clarinete (de 2 a 3 ) em delay de tempo variável e cuja primeira audição se deu no Porto no mesmo ano. De Sang-ge-Sang existem igualmente duas versões. A primeira, para fagote, data de 1976; a segunda, para fagote a três partes, data de 1779 .
} 

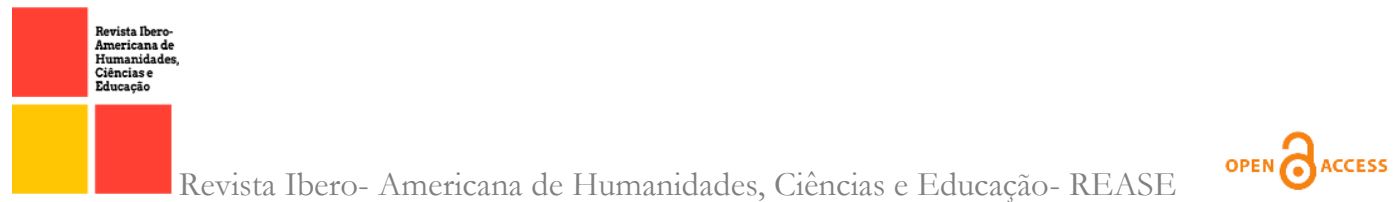

$\mathrm{CDs} /$ monográficos, além de outras peças gravadas em mais de $50 \mathrm{CDs}$ publicadas em diversos países. Cinquenta e seis peças foram compostas em comissão. A sua obra é tocada pelos músicos mais conceituados da atualidade, quer nacional, quer internacionalmente. No ano de 2019, houve mais de Ioo apresentações em mais de 20 países. Em relação aos concursos, João Pedro Oliveira tem sido um dos compositores mais premiados a nível internacional; do seu currículo constam já 54 prémios ou Menções Honrosas, 25 foram primeiros prémios, entre outros: o Prémio Bourges Magisterium, Prémio Giga-Hertz, Prémio Música Nova e Concurso Metamorfose. Já escreveu mais de ıo artigos/capítulos de livros que falam dele e da sua obra. O compositor é ainda autor e coautor, publicou um livro de análise e 2i artigos e capítulos sobre diversos temas (TELLES, 2019).

\section{I Características e influências na obra de João Pedro Oliveira}

As artes no século XX e XXI vão progredir em simultâneo entre extremos, a liberdade, com a abolição de todas as regras, o constrangimento, o excesso de regras, o experimentalismo e o pós-modernismo. É neste cenário que João Pedro Oliveira cria a sua própria identidade como compositor, e isso reflete-se nas sonoridades muito pessoais nas suas obras. As obras do compositor francês Olivier Messiaen, também organista, irão influenciar muito a forma de compor de João Pedro Oliveira, através da conjugação entre a razão e a espiritualidade. Neste sentido, Alexandre Delgado diz o seguinte: "[t]al sentimento não surge por acréscimo, mas como razão de ser do próprio acto criativo: Cada obra de João Pedro Oliveira é peça de um mosaico em cujo cerne se encontra o Livro do Apocalipse" (DELGADO, 2003, p. II). O equilíbrio entre a razão e a espiritualidade na forma de compor de João Pedro Oliveira é, sem dúvida, uma característica sempre presente nas suas obras. Uma característica importante que define o estilo muito pessoal de João Pedro Oliveira nas suas obras é a conjugação sublime que o compositor consegue na articulação entre os instrumentos acústicos: o acústico e as ferramentas fornecidas pelo computador: a eletrónica, onde ambas as partes se complementam de uma forma quase perfeita.

Apesar das transformações ocorridas durante o século XX, não se pode esquecer o que foi criado no passado.

\footnotetext{
Desde o início do século $X X$ que a concepção e composição do som, a preponderância do timbre face aos outros parâmetros sonoros, a atomização dos motivos melódicos, a aperiodicidade e a descontinuidade temporal são elementos que ganham uma maior relevância na concepção, organização e desenvolvimento discursivos (POMBO, 2003, p. 16-17).
}

Grande parte dos compositores no século XX e XXI utilizam nas suas obras processos extramusicais, isto é, recorrem muitas vezes à palavra, a cálculos matemáticos e até mesmo a histórias, entre outros elementos para a realização das suas obras. Enquanto esses processos extramusicais podem ou não depender do seu significado, já em relação à música por si só, não depende desses mesmos significados, mas, pode servir-se desses mesmos elementos para reforçar e intensificar as suas ideias musicais. 


\section{Obra: Pirâmides de Cristal}

Na sua obra Pirâmides de Cristal para piano solo, João Pedro Oliveira, demonstra e aplica os seus conhecimentos noutras áreas do saber, e utiliza como elemento extramusical o fractal. Segundo Santana H. e Santana R. (2004, p. 96): “[u]m fractal é assim uma forma geométrica irregular ou fragmentada que pode ser subdividida em partes, e em que cada uma delas, pelo menos aproximadamente é uma cópia reduzida da forma do todo".

O compositor nesta obra busca as variações tímbricas, muito característico do velho estilo, em articulação com outras técnicas atuais que podemos definir como o novo estilo, tais como: a transformação tímbrica, a variação constante das sonoridades, a utilização dos pedais, as formas de ataque das notas, as dinâmicas, os fraseados e a harmonia tímbrica, umas vezes cerrada, outras vezes mais aberta em diferentes registos do instrumento. $\mathrm{O}$ compositor utiliza muito o gesto musical ${ }^{5}$, de uma forma e complexidade variável:

Este facto origina uma paleta de cores musicais diversificada, que se desenvolvem, transformam, opõem ou fundem no espaço e no tempo originando um cristal de contornos, brilhos e matrizes que se nos apresenta de um modo novo, agarrando a obra de uma forma bastante forte, à realidade e às ideias musicais transmitidas pelo compositor, revelando uma característica do fractal, a dimensionalidade (SANTANA, 2003, p. 53).

A utilização do elemento rítmico-harmónico é outra característica recorrente em toda a obra com base no gesto musical, de uma forma mais densa ou menos densa. Podemos também verificar a utilização do gesto musical ao longo de toda a obra na criação de tensões e distensões através das dinâmicas, assim como na fragmentação harmónica, e na utilização da mesma por vários registos do instrumento. Em relação à estrutura formal da obra, e partindo do princípio de que o fractal é uma estrutura que mantém algumas características independentemente do nível do qual as observamos, o compositor consegue conjugar todos os elementos musicais falados anteriormente de uma forma sublime e criar colorido muito pessoal.

\section{Breve biografia de Sérgio Azevedo}

Sérgio Azevedo (1968) começou a estudar música com o seu pai Octávio Sérgio. Aos quatro anos iniciou o estudo de Piano, Guitarra Clássica e Formação Musical com professores particulares. O contacto com quase todo o tipo de música, desde a folclórica até à erudita, fez com que influenciasse mais tarde toda a sua música desde os primeiros tempos como compositor. Anos mais tarde ingressa na Academia Amadores de Música onde começou a estudar Composição com Fernando Lopes Graça. Concluiu os seus estudos superiores de Composição com a classificação máxima na Escola Superior de Música de Lisboa, tendo trabalhado com Constança Capdeville e Christopher Bochmann. Fez o

\footnotetext{
5 Não existe uma definição que seja consensual no meio musical, podendo o termo ser sujeito a várias interpretações. $\mathrm{Na}$ arte musical este termo está normalmente associado à área da composição no que diz respeito à análise musical, por esse motivo é normal encontrar diferentes abordagens no meio musical quando se fala no termo gesto musical. Uma das características deste termo é que gesto musical está relacionado com a consciência corporal. De uma forma geral o termo gesto está associado a diferentes tipos de movimento e às funções que podem realizar.
} 
Doutoramento no Instituto de Estudos da Criança, da Universidade do Minho, sob a orientação da professora doutora Elisa Lessa e coorientação do professor doutor Christopher Bochmann. Frequentou diversos seminários e cursos com Emmanuel Nunes, Jorge Peixinho, Tristan Murail, Philipe Manoury, Luca Francesconi, Mary Fintsterer, Louis Andriessen, Simon Bainbridge, IRCAM. Ao longo da sua carreira já foi premiado por diversas vezes, quer nacionalmente, quer internacionalmente, com destaque para o Prémio das Nações Unidas. As suas obras têm sido encomendadas e tocadas em vários países pelos mais prestigiados intérpretes e algumas das suas obras estão editadas em CD. Colabora com regularidade com revistas e dicionários nacionais e internacionais. Em 1999 publicou o livro A Invenção dos Sons, uma panorâmica dos compositores contemporâneos portugueses. Escreveu diversos artigos para a edição 2000 do New Grove Dictionary of Music and Musicians e colabora com outras prestigiadas publicações e instituições musicais, como o Centro de Estudos de Sociologia e Estética Musical (CESEM), na divulgação da música portuguesa contemporânea. Foi professor na Academia Amadores de Música, Academia Luísa Todi, na Universidade Nova de Lisboa, na Orquestra Metropolitana de Lisboa, e é desde 1993 professor na Escola Superior de Música de Lisboa.

\section{I Características e influências na obra de Sérgio Azevedo}

Uma boa parte da obra do compositor, como canções para coro infantil e piano sobre textos do próprio compositor, teatros musicais, entre outras obras, é destinada a crianças. Segundo o compositor, em Portugal, basicamente, temos dois tipos de obras dedicadas a crianças:

\footnotetext{
I.Aquelas que são pensadas para que nelas as crianças tenham, no todo ou em parte essencial, um papel activo (canções para coro e piano ou ensemble, óperas ou cantatas infantis com acompanhamento de piano ou ensemble/orquestra nas quais algumas partes vocais e instrumentais estão ao alcance da técnica musical da criança, como The Little Sweep e Noah's Fludde de Benjamin Britten, etc.). 2.Aquelas que são destinadas às crianças apenas como ouvintes, devido à dificuldade de execução da música, e que por essa razão colocam as crianças num papel passivo, não interveniente (contos narrados como Pedro e o Lobo de Serguei Prokofiev, óperas infantis ou obras orquestrais puras como L'Enfant et les Sortilèges e Mar Mére L'Oye de Maurice Ravel, obras didáticas como o Guia dos Jovens para a Orquestra de Benjamin Britten, etc.) (RAPOSO, 2009, p. 2I).
}

O interesse pela Composição de música para crianças vem já desde o início da sua carreira como compositor, onde se destacam as Cinco Cantigas de Bichos compostas em 1996 a convite da maestrina Paula Coimbra para o CD Loik. Segundo o próprio compositor: "[o] facto de não ter existido outro projeto de gravação ou interpretação na altura, e de as primeiras canções serem tão cantadas e apreciadas, pode ter influenciado o facto de não ter continuado a compor para coro infantil” (RAPOSO, 2009, p. 17-18). Este ciclo de obras não obteve o resultado esperado, no sentido de surtirem novas composições, e só passados dez anos é que surgiram novas encomendas.

\section{Obra: Jogos de Pássaros}

O Concerto para Flauta Jogos de Pássaros, escrito em 2016, contêm uma grande concentração expressiva; o material de base é constantemente reiterado no discurso, como 
que se de uma grande árvore se tratasse (o tema base), uma árvore que é rodeada por pássaros que esvoaçam à sua volta das volúveis figurações que rodeiam o tema.

\begin{abstract}
A ideia da flauta como tradutora, pela agilidade e sonoridade aguda, dos pássaros, é antiga, escreve Azevedo, na apresentação da obra, assegurando que não quis imitar deliberadamente o canto dos pássaros (exceto na cadência da orquestra no início do $5 .^{\circ}$ andamento) (AGÊNCIA LUSA, 2017, s. p.).
\end{abstract}

O compositor refere ainda o seguinte em relação ao Concerto para Flauta, e reforça com estas palavras:

\begin{abstract}
Quis antes criar algumas metáforas musicais, como a da árvore antes referida. O movimento de conjunto de bandos de pássaros e da sua 'dança' aérea coordenada também me deu algumas ideias, mas, repito, todas elas se traduziram quase sempre em estruturas musicais abstratas e não em imitações deliberadas desses fenómenos (AGÊNCIA LUSA 2017, s. p.).
\end{abstract}

Sérgio Azevedo destaca a cadência orquestral, com que se inicia o 5.․․ Andamento, que aponta como um momento excecional. Nesse sentido afirma o seguinte: "[a]í, cada instrumento de sopro das madeiras e algumas cordas solistas se transformam em diferentes pássaros, criando uma textura quase improvisada, que precede a cadência para a flauta solo" (AGÊNCIA LUSA, 2017, s. p.). A composição foi dedicada ao flautista Nuno Inácio, r.o flautista da Orquestra Metropolitana de Lisboa, e também à memória do musicólogo Carlos de Pontes Leça, antigo diretor adjunto e consultor do Serviço de Música da Fundação Calouste Gulbenkian.

\title{
6 Breve biografia de Sara Carvalho
}

Sara Carvalho (1970) é professora do Departamento de Comunicação e Arte da Universidade de Aveiro e investigadora do centro de Etnomusicologia - Centro de Estudos de Música e Dança em Composição e Educação em Música. Como compositora tem mais de 50 obras, na sua maioria encomendas de instituições diversas: ensembles e músicos de prestígio internacionais, tais como: Orquestra Metropolitana; University of York Chamber Orchestra; Oficina de Música Viva; Ensemble Neue Musik Bratislava; Medea String Quartet; Remix Ensemble; Henrique Portovedo; Pedro Rodrigues; Liviu Scripcaru; Mieko Kanno, entre outros. De realçar que as suas obras são tocadas com regularidade tanto a nível Nacional como internacional. Grande parte das suas composições está gravada em CD e muitas das suas obras estão publicadas no Centro de Informação \& Investigação da Música Portuguesa. No ano de 2012 foi lançado o seu primeiro CD monográfico, 7 Pomegranate Seeds, editado pela numérica.

Relativamente à área da Educação em Música tem desenvolvido investigação em processos criativos no desenvolvimento do pensamento musical, com temáticas tão variadas como: criatividade na educação, otimização do ensino e aprendizagem na sala de aula, educação musical para adultos, influência de projetos musicais artísticos na escola e/ou comunidade, emoção e fluxo em contexto musical. Apresenta-se com regularidade em conferências nacionais e internacionais; o seu trabalho está publicado em diferentes periódicos e capítulos de livros. Além disso, é convidada com regularidade, também, para 

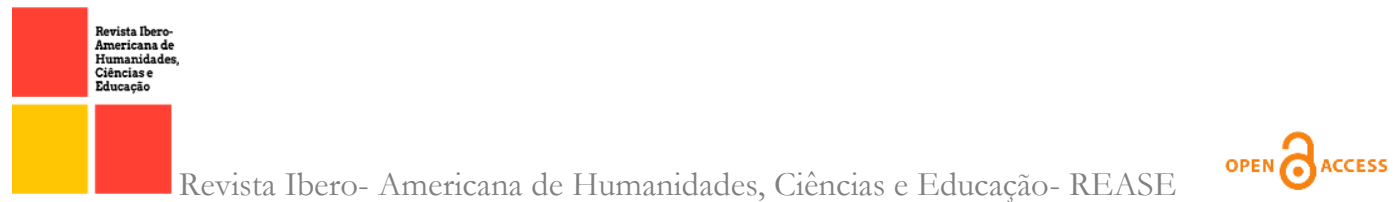

integrar o painel de peritos da Comissão Europeia, para avaliar os programas Cultura e Europa Criativa.

\section{I Características e influências na obra de Sara Carvalho}

Sara Carvalho, como compositora, tem já uma extensa experiência em domínios, nomeadamente: a interação das artes performativas, enquanto extensão e transformação do pensamento musical, assim como em aspetos relacionados com narrativa musical, gesto e colaboração compositor-performer.

\section{Obra: Spinning Yarns e Spinning Yarns II}

$\mathrm{Na}$ sua obra Spinning Yarns, a compositora utiliza técnicas, tais como: o gesto musical, a indeterminação e a composição colaborativa. Não existindo uma definição que seja consensual no meio musical, como já foi referido anteriormente, podendo este termo adquirir várias interpretações; Sara carvalho refere o seguinte: "[é] importante refletir sobre a ideia de que gesto pode produzir e sugerir, pois os gestos evocam significado" 6 (CARVALHO, 2019, s. p., tradução nossa). Em relação à indeterminação, podemos recorrer à Idade Média, para perceber de que forma a interação entre o compositor e o interprete está presente na música. Numa primeira fase, a falta de uma notação adequada (neumas/sinais) para que o compositor pudesse especificar as suas ideias na partitura, levou os criadores a conceberem alguma liberdade aos intérpretes para a execução das partituras. Fatores como: a altura dos sons e a sua duração até ao século XV, mais tarde a opção entre as vozes na música polifónica no século XVI, a instrumentação opcional no século XVII, o baixo contínuo onde o cravista improvisava sobre a linha do baixo da partitura, os ornamentos melódicos nos séculos XVII e XVIII, a inclusão da famílias dos sopros de metal na orquestra sinfónica no século XVIII e o aumento do número de sinais de dinâmica que assistimos no século XIX, são alguns aspetos que contribuíram para colmatar um défice de sinais capazes de fazer representar as ideias do compositor na pauta (CARVALHO, 2019).

Durante o século XX os compositores, com o surgimento das novas ferramentas e os meios eletrónicos, tentam controlar a execução dos parâmetros descritos anteriormente. Os compositores que mais trabalharam a indeterminação foram, John Cage, Stockhausen, Charles Ives, Henry Cowell e Pierre Boulez. O termo foi utilizado por John Cage, que se inspirou no I-Ching para desenvolver a ideia de não intenção na música.

[...] alguns compositores, como John Cage [...], a partir da segunda metade do século, passaram a deixar alguns elementos da sua obra à mercê do acaso ou da opção do intérprete. É o nascimento da música indeterminada, que muitos autores e compositores chamam de aleatória. Com ela, surgem novas formas de notação musical, como partituras gráficas ou textuais, que especificam os elementos da linguagem musical com um grau de precisão bem menor. A liberdade do intérprete torna-se muito maior e a própria relação compositor-intérprete ganha um novo formato (ROCHA, 20or, p.I4).

\footnotetext{
${ }^{6}$ Original: "It is important to reflect on the idea of what gesture can both produce and suggest, as gestures evoke meaning" (CARVALHO, 2019, s.p.).
} 
A indeterminação, pode assim ser aplicada ou preparada, tanto pelo compositor no ato da composição, como pelo intérprete no ato da execução, obtendo um resultado sempre diferente de apresentação para apresentação.

A composição colaborativa é ainda um tema bastante complexo, que pode ser abordado de diferentes perspetivas, o que dificulta a articulação entre os conhecimentos e a prática pedagógica. No entanto, a composição colaborativa já vem de tempos anteriores, tendo atingido grande escala durante o século XX. O interesse académico por esta temática da colaboração entre compositor e performer advém, principalmente, desde o final do século XX, início do século XXI (DOMENICI, 2013). Na obra Spinning Yarns (Os fios Giratórios) Sara Carvalho diz o seguinte:

Esta peça foi uma encomenda feita por/para duas mulheres pianistas, que serviu de ponto de partida para a concretização desta obra. $O$ interior do piano serviu de inspiração para a compositora que à semelhança dos "teares" duas mulheres o manipulavam e misturavam as suas histórias como se fosse numa tapeçaria. $O$ nome 'fiação' foi inspirado na expressão "fiar um fio", que significa contar uma história, que em certo lugar contém uma certa quantidade de exagero. Para gerar as estruturas e materiais a compositora observou as mulheres a tocar piano e analisou os seus gestos. Enquanto compunha a peça, o objetivo era refletir sobre diferentes formas e gestos físicos e musicais, inspirados na ação da tecelagem, e como tal associou os gestos das pianistas ao movimento dos artesãos ${ }^{7}$ (CARVALHO, 2019, s. p.).

$\mathrm{Na}$ sua obra Spinning Yarns II, para dois pianos, Sara Carvalho recorre ao gesto musical e à indeterminação para a construção/idealização da sua peça. Nesta obra o gesto musical tem a função de ampliar auditivamente certos eventos musicais, o que permite aos instrumentistas nunca tocarem a peça sempre da mesma maneira, dando alguma liberdade ao músico de forma que cada concerto tenha sempre algo de novo (improviso). Para que isso aconteça, a compositora não oferece uma partitura definida ao intérprete, mas dá contextos musicais que permitem essa liberdade ao intérprete para criar novas e diferentes narrativas, e condições para que as mesmas possam ocorrer. Neste sentido, Sara Carvalho realça o seguinte: "[o] objetivo não é apenas compartilhar procedimentos, mas também estimular a discussão sobre os processos de composição colaborativa"8 (CARVALHO, 2019, s. p., tradução nossa). No que diz respeito à estrutura da peça esta encontra-se dividida em três partes distintas, que devem ser tocadas sem interrupção.

A obra está dividida em três secções que devem ser tocadas sem interrupção. $\mathrm{Na}$ secção A a ideia é criar gestos espelhados muito rigorosos, como se os gestos musicais estivessem a ser intensificados através de um movimento físico. A secção

\footnotetext{
7 Original: "The piece was commissioned by/for two female pianists, and my starting point was the women and the instruments themselves. In terms of narrative I imagined the inside of the pianos as being looms, and that the two women were spinning them, while mixing their stories into their tapestries. The title "spinning yarns" is inspired by the expression "to spin a yarn", which means to tell a story, that somewhere contains a certain amount of exaggeration. In order to generate my music structures and material, I observed the women playing the piano, and analyzed their body gestures. While writing the piece the objective was to reflect on different forms of physical and musical gestures, inspired by the action of weaving, and how I associated the female pianists' gestures with the movement of the artisans" (CARVALHO, 2019, s. p.).

${ }^{8}$ Original: "The objective is not only to share procedures, but also stimulate discussion on the collaborative composition processes" (CARVALHO, 2019, s. p.).
} 
B é uma parte improvisada em que as duas pianistas aquando da improvisação devem-se afastar das estruturas do material ouvido anteriormente. $\mathrm{Na}$ secção $\mathrm{C}$ a ideia é que os espelhamentos dos gestos ficassem fora de fase ${ }^{9}$ (CARVALHO, 2019, s. p., tradução nossa).

Por fim, a compositora argumenta o seguinte em relação à sua obra, para concluir:

Embora não seja possível ao ouvinte detetar as minhas imaginações de género, as minhas estruturas e materiais musicais pretendem transmiti-las, operando com significantes ocultos de género. Esta apresentação refletirá sobre o meu pensamento musical, gestos marcados por género, que por questões de improvisação e a construção de uma narrativa compartilhada, com base para um procedimento colaborativo eficaz entre o compositor $e$ o interprete $e^{10}$ (CARVALHO, 2019, s. p., tradução nossa).

Esta obra em análise reflete as tendências composicionais da compositora Sara Carvalho.

\section{Breve biografia de Fernando Lapa}

Fernando Lapa nasceu em Vila Real em 1950 e estudou no Conservatório de Música do Porto, onde concluiu o Curso Superior de Composição na classe do professor/compositor Cândido Lima. As suas obras abrangem quase todos os géneros musicais: concertos, repertório sinfónico e coral-sinfónico, ópera, música de câmara, obras para instrumento solo, bandas sonoras para cinema e teatro.

Algumas das suas obras são interpretadas, quer em Portugal, quer no estrangeiro, como Espanha, França, Itália, Bélgica, Áustria, Polónia, Hungria, Noruega, Finlândia, Macedónia, Eslovénia, Egipto, Índia, Japão, Singapura, México, Brasil, Canadá, EUA. Algumas das suas obras foram gravadas e transmitidas pela Rádio Televisão Portuguesa (RTP), Rádio Difusão Portuguesa (RDP), Antena 2, e outras estações de rádio e televisão nacionais e internacionais. Tem partituras editadas em Portugal e na Alemanha. Lecionou em diversas escolas como professor de Análise e Técnicas de Composição (ATC), de Composição, Orquestração e outras disciplinas no Conservatório de Música do Porto e na Escola Superior de Música e das Artes do Espetáculo do Porto. Tem participado em vários seminários e colóquios, sendo convidado com regularidade para integrar o júri de diversos prémios e concursos.

Nunca fui uma pessoa de inscrição em clubes, seitas, academias, escolas. Tolerante por natureza (qualidade que é por vezes o meu maior defeito) sempre prezei a

\footnotetext{
9 Original: "Spinning Yarns (II) is formally divided in three sections, which should be played without any interruption. In the first part (A), the idea was to create very rigorous mirroring gestures, as if the musical gestures were being intensified through the physical movement. Section B is of improvisational construction, and the two pianists depart their improvisation from structures of previously heard material. In the last section (C) the idea was that the initial mirroring of the gestures become out of phase" (CARVALHO, 2019, s. p.).

1o Original: "I will argue that while it might not be possible for a listener to detect my gender imaginings, my musical structures and material intend to transmit them, operating as concealed signifiers of gender. This presentation will reflect on my compositional thinking, gender-marked gestures, improvisational issues, and the construction of a shared narrative, as basis for effective performer-composer collaborative procedure" (CARVALHO, 2019, s. p.).
} 
minha liberdade e independência, mas nunca fiz disso bandeira ou militância. Consigo conviver com diversas estéticas ou correntes, sem qualquer espécie de filiação ou de fidelidade exclusiva ou sem que necessite de «assinar» a respetiva «ficha de inscrição» (LAPA, s. d., s. p.).

\section{I Características e influências na obra de Fernando Lapa}

A maior parte das obras de Fernando Lapa são encomendas de instituições ou de particulares, o que permite ao compositor realizar diversificadas experiências e que por sua vez condicionam a sua forma de compor e até mesmo de o condicionar na sua abordagem a cada obra com novos elementos e formatos. Como já foi referido anteriormente, pelo próprio compositor, a sua obra abrange diversas correntes estilísticas do século $\mathrm{XX}$, sem que se tivesse ligado completamente a uma dela. Neste sentido, na sua obra, podemos encontrar diversas influências de compositores, tais como: Luciano Bério, Magnus Lindberg, Olivier Messian, Béla Bartók, György Ligeti, Alban Berg, Anton Webern e Arnold Schönberg.

A música está cheia de escolhas, de gostos, de tensão, de dimensão espiritual, de vontade de dizer coisas. Muitas vezes há um julgamento muito apressado, ao dizer que determinada música é esquisita, agressiva, agreste, dissonante! Mas até poderá ter as coisas todas, como toda a música tem! (LAPA, s. d., s. p.).

Devido à sua forte ligação com a música coral o compositor admira a polifonia portuguesa do passado dos séculos XVI e XVII. Dos compositores portugueses Lapa identifica-se muito com Lopes-Graça e Claudio Carneyro; deste último admira o requinte, a simplicidade e a originalidade das suas obras. Lapa não esconde a sua admiração, ainda, por compositores como Johann Sebastian Bach, Wolfgang Amadeus Mozart, Robert Schumann, entre outros. Em relação a esta admiração por todos estes compositores, Lapa diz o seguinte:

Não estou a dizer que tenha afinidades estéticas com todos estes compositores ou que componha como eles. Estou apenas a dizer que os aprecio na sua forma de ser e de estar, que admiro o equilíbrio que conseguem, a originalidade, a raça, a individualidade que conseguem pôr naquilo que fazem (LAPA, s. d., s. p.).

\section{Obra: No Coração do Porto}

Na sua obra No Coração do Porto o compositor refere o seguinte:

Esta obra segue a par e passo o expressivo poema de Vasco Graça Moura, que lhe emprestou o título. A sua escrita corrida, narrativa e horizontal, retrata a nossa cidade em pinceladas seguras e únicas. Tal como uma aguarela. Ainda que o poema deva ser lido como um todo, há em cada uma das estrofes um certo traço peculiar que me sugeriu diversas e individualizadas opções de escrita musical. Quase poderia falar de "andamentos", pese embora a brevidade de cada um. Mais narrativa, a primeira estrofe desenrola-se numa escrita plana, de tratamento homofónico e silábico. Os registos extremos de que o poema se faz eco ("a fonte jorra" e "a noite forra figurinhas escuras do Alvarez") sugerem uma diversa cor harmónica, alternando entre claro e escuro. O gesto progressivo e crescente de "é quando sai do ventre da manhã", que lemos na segunda estrofe, remete para o mundo da polifonia. Essa teia de vozes, que tem tanto de essencial e simplificado, quanto de gesto orientado e dinâmico, vai projectar-se finalmente em "o som 


\begin{abstract}
contra o granito" num evidente sublinhado, no registo agudo. "do coração do porto até ao mundo", o verso com que termina a terceira estrofe, constitui a meu ver a afirmação central de todo o poema, sublinhando a vocação universalista de uma universidade cada vez mais voltada para o exterior. A escrita é por isso mesmo afirmativa e aberta, na única passagem em toda a obra em que se aproxima de um hino. A última estrofe alude às sombras do presente, num registo mais crepuscular, surgindo uma tradução musical menos linear e imediata. No entanto o poema termina com um verso tão inesperado, quanto sugestivo: "mas nele (gilreu) empoleirou-se uma gaivota”. Esta imagem feliz, que sintetiza bem o caractér da cidade, conduziu-me a uma breve recapitulação das duas frases essenciais do poema: "no coração do porto jorra" e "do coração do porto até ao mundo". Resta acrescentar que circula, por esta música, um sentido positivo, servido por uma escrita transversal e abrangente, mais preocupada em juntar do que em separar. As sonoridades abertas de grande parte da harmonia - particularmente sublinhadas em "a fonte jorra", "ventre da manhã", "o sol contra o granito", "um fio de luz" ou "até ao mundo" - revelam uma vez mais o meu eterno fascínio pela cor e pela luz. E acrescentam o olhar maravilhoso e cúmplice com que vejo esta cidade única. "no coração do porto", para coro e orquestra, foi encomendada pela universidade do Porto, para assinalar o seu centenário (LAPA, 20II, s. p.).
\end{abstract}

Podemos verificar nesta obra a diversidade e o conhecimento que Fernando Lapa demonstra ter a respeito das diferentes técnicas de compor, assim como em relação a estilos musicais de diferentes épocas. As palavras que utiliza para explicar a sua obra como: aguarela (pintura) quando se refere ao poema, demostra a sua diversidade na escrita musical. A palavra gesto, a ênfase a determinadas frases do texto, quando refere uma escrita transversal e abrangente, mais preocupada em juntar que separar, e sonoridades abertas, são termos que caracterizam a diversidade de escrita musical do compositor.

\title{
CONSIDERAÇÕES FINAIS
}

Durante o século $\mathrm{XX}$, assistimos a um conjunto de transformações políticas, económicas, sociais e a um crescimento cultural que coloca a nossa cultura e os nossos artistas, num caminho evolutivo que já se vinha manifestando um pouco por todo o Ocidente. A mudança de paradigma que teve como percursor Luís de Freitas Branco (I89o1955), considerado o introdutor do modernismo musical em Portugal, ocorreu e permitiu assistir a um reajuste gradual, e a um novo enquadramento das velhas estruturas do passado, com as novas ferramentas composicionais ao dispor dos compositores na atualidade.

$\mathrm{Um}$ aspeto pertinente a realçar prende-se com o facto de todos os compositores referenciados neste artigo (Cândido Lima, João Pedro Oliveira, Sérgio Azevedo, Sara Carvalho e Fernando Lapa), não se desligarem completamente das suas raízes culturais, talvez pelo facto de ainda termos uma percentagem da população portuguesa com raízes de uma sociedade rural, e que, direta ou indiretamente, seja uma fonte de inspiração para os nossos compositores, assim como o equilíbrio encontrado nas suas obras com a nova música e as novas ferramentas composicionais ao dispor dos mesmos.

Podemos encontrar características nos cinco compositores já referidos que são de certa forma comuns. De facto, todos tem uma linguagem bastante pessoal, e com muitas influências do meio em que estão inseridos, como já foi referenciado anteriormente.

O conceito de liberdade é um termo que pode definir de uma forma muito abrangente a obra dos cinco compositores abordados, nomeadamente no que diz respeito aos 
diferentes contextos sociais em que viveram e vivem, assim como na forma como desenvolvem as suas estruturas rítmicas e melódicas e até mesmo temporais. Um outro aspeto a realçar nas suas obras é a forma como cada um cria e estratifica os seus temas, partindo do gesto musical, característica comum a todos eles que o utilizam sempre de uma forma muito diversificada e colorida; gesto musical a partir das harmonias e de um fraseado muito pessoal, fazendo com que a audição seja fluente.

Podemos concluir, de uma forma geral, que recorrem e respeitam as técnicas seculares, que podem servir de base para as suas criações, e ao mesmo tempo conseguem inovar e serem criativos na manipulação das novas ferramentas que encontram ao seu dispor.

\section{REFERÊNCIAS}

AGÊNCIA LUSA. Orquestra Metropolitana de Lisboa estreia obra de Sérgio Azevedo. Lisboa: [s. n.], 2017.

Disponível em: <https://www.noticiasaominuto.com/cultura/8or6i2/orquestrametropolitana-de-lisboa estreia-obra-de-sergio-azevedo>. Acesso em: 20 jul. 2020.

AZEVEDO, Sérgio. “Cândido Lima: vers une Gesamtkunstwerk? Ensaio quasi una fantasia”, Cândido Lima, Porto, Atelier de Composição, 2002. p. 13-45.

CARVALHO, Sara. Tracing the creative process in music. [s.l.]: [s.n.], 2019. Disponível em: < http://tcpm2org.fcsh.unl.pt/sara-carvalho/>. Acesso em: i8 jul. 2020.

CASTRO, Paulo Ferreira de. Tempo, modernidade e identidade na música portuguesa do século XX. In: COSTA, J. A. (Coord.). Olhares sobre a história da música em Portugal. Matosinhos: Verso da História, 2015. p. 213-247.

DELGADO, Alexandre. A ficção do tempo. In: MAIA. P. J. (Ed.). Compositores portugueses comtemporâneos II: João Pedro Oliveira. Porto: Atelier de Composição, 2003. p. 13-21.

DOMENICI, Catarina Leite. It takes two to tango: a prática colaborativa na música contemporânea. Revista do Conservatório de Música da UFPel, Pelotas, n. 6, p.I-I4, 2013.

LAPA, Fernando. Grande entrevista: Fernando Lapa (Parte I). Da Capo, Portugal, [s.1.]. Disponível em: < http://www.dacapo.pt/seccao-Compositores\&-Grande-EntrevistaFernando-Lapa-(parte-I) >. Acesso em: 22 jul. 2020.

LAPA, Fernando. Concerto comemorativo do centenário da Universidade do Porto: música sinfónica portuguesa. Porto: Universidade do Porto, 20II. Disponível em: $\langle$ https://sigarra.up.pt/up/pt/noticias_geral.ver_noticia?p_nr=IIo86〉. Acesso em: 20 jul. 2020.

LIMA, Cândido. “Livre. Sem Limites (Quase...)”. In: MAIA, P. J. (Ed.). Cândido Lima. Porto: Atelier de Composição, 2002. p. 79-8o. 
MOREIRA, Vânia Filipa Tavares. De Luís de Freitas Branco a Alexandre Delgado: uma linhagem de compositores que marcou a escrita musical do século vinte em Portugal. Dissertação (Mestrado em Música-Área de Especialização Violoncelo). Escola Superior de Artes Aplicadas, Instituto Politécnico de Castelo Branco, Castelo Branco, 2014.

OLIVEIRA, João Pedro. Entrevista. In: Compositores portugueses dos séculos XX e XXI, Dossier no 17: João Pedro Oliveira. Parede: Miso Music Portugal, 2017. p.5-Ir. Disponível em: $\langle$ http://mic.pt〉. Acesso em: 2 out. 2018.

POMBO, Fátima. Em Busca do Mistério. In: MAIA. P. J. (Ed.). Compositores portugueses comtemporâneos II: João Pedro Oliveira. Porto: Atelier de Composição, 2003. p. II-I2.

RAPOSO, Joana Mendez. Das palavras à música: as canções infantis para coro e piano de Sérgio Azevedo sobre textos próprios (2007-2009) e o seu papel no enriquecimento estético do imáginário portugês. Dissertação (Mestrado em Estudos da Criança - Educação Musical). Instituto de Estudos da Criança, Universidade do Minho, Braga, 2009.

ROCHA, Fernando de Oliveira. A Improvisação na música indeterminada: Análise e performance de três obras brasileiras para percussão. Dissertação (Mestrado em Performance Musical). Programa de Pós-Graduação em Música, Escola de Música da Universidade Federal de Minas Gerais, Belo Horizonte, 20or.

SALAZAR, Álvaro. Para um retrato de João Pedro Oliveira.In: MAIA. P. J. (Ed.). Compositores portugueses comtemporâneos II: João Pedro Oliveira. Porto: Atelier de Composição, 2003. p. 85-103.

SANTANA, Helena. «Piramides de Cristal» o fractal como princípio estrtutural do discurso musical. In: MAIA. P. J. (Ed.). Compositores portugueses comtemporâneos II: João Pedro Oliveira. Porto: Atelier de Composição, 2003. p. 51-64.

SANTANA, Helena; SANTANA, Rosário. Semi-breves: notas sobre música do século XX. Aveiro: Universidade de Aveiro, 2004.

SANTANA, Helena; SANTANA, Rosário. Autómatos da Areia (1978/84), Lendas de Neptuno (1987) e Ocenanos (1978/79) de Cândido Lima: como o som concreto se torna outro nos primeiros trabalhos electroacústicos do compositor. In: EAW2015 A TECNOLOGIA AO SERVIÇO DA CRIAÇÃO MUSICAL, 2015, Aveiro. Atas... Aveiro: Universidade de Aveiro, 2015. p. 89-94.

TELLES, Ana. Traços da prática organística na escrita para piano e electrónica de João Pedro Oliveira: In: MARTINGO, Â; TELLES, A. (Eds.). Tempore, Abyssus Ascendens ad Aeternum Splendorem, Timshel e Entre o Ar e a Perfeição. Música instrumentalis: experimentação e técnicas não convencionais nos séculos XX e XXI. Vila Nova de Famalicão: Edições Húmus, 2019. p. ı63-190. 